JÓZEF MATUSZEWSKI

\title{
Datowanie w dekretach krakowskich
}

\section{Datierung in den Krakauer Dekreten}

1. Terminy datujące w dekretach. 2. Znaczenie poszczególnych terminów.

1. Datierende Termini in den Dekreten. 2. Bedeutung der einzelnen Termini.

1. W dekretach ${ }^{1}$ mamy następujące terminy datujące chronologicznie, pierwotnie lub wtórnie. Zestawiamy je alfabetycznie:

lacińskie: adventus, annus, ascensio, autumnus, circumcisio, in crastino, dies, dominica, epiphania, etas, feria, ferialis, feriatus, extra feriatus, festivitas, festum, hora, ligatus (dies), mane, mensis, meridie, nativitas, nox, occasus solis, octava, prandium, profestum, quatember, quatuor tempora ${ }^{2}$;

niemieckie: frist, groß, helig (tag), jahr, monat, morgen, sonnenschein, tag (dingtag, lebetag), woche, zeit.

2. Wyjaśnienie terminów:

1. Adventus, adwe nt. Wyraz adventus pojawia się w dekretach w dwu znaczeniach:

a. Dosłownym - przybycia, 1.508: sed suspenderunt ad adventum domini, 2.597: suspendere causam ad adventum cursoris ${ }^{3}$.

b. Tę samą nazwę nadano również okresowi czterech niedziel ${ }^{4}$ poprzedzających święta Bożego Narodzenia. Przyswoił ją sobie język polski

${ }^{1}$ Decreta iuris supremi Magdeburgensis castri Cracoviensis. Die Rechtssprechung des Oberhofs des deutschen Rechts auf der Burg zu Krakau 1456-1481, t. 1, Herausgegeben und eingeleitet von Ludwik Lysiak und Karin Nehlsen-v. Stryk, Frankfurt am Main 1995; t. 2: 1481-1511. Herausgegeben und eingeleitet von Ludwik Łysiak unter Mitwirkung von Karin Nehlsen-v. Stryk, 1997.

${ }^{2}$ Wydawca drukuje niepotrzebnie wyrazy quatember i quatuor tempora duża literą - to appellativa.

${ }^{3} \mathrm{~W}$ tym samym dekrecie mowa o tarditas cursoris.

${ }^{4}$ Nie czterech tygodni! 
w postaci nie zmienionej - jako adwent. To właśnie trzema względnie czterema niedzielami adwentu rozpoczyna się rok kościelny: 1. adventus, 2. $a d v .$, 3. $a d v .$, 4. $a d v$.

2. Annus, rok. Jest to rok Pański, annus Domini, liczony od narodzenia Chrystusa, stąd zwany także 1.206: annus Nativitatis. W dekretach podaje się go tylko przy pierwszym akcie kolejnego roku, pomijając przy następnych.

3. Datacja. Pisać pełnymi słowami anno millesimo-guadringentesimo-nonagesimo-guarto to sposób dość kłopotliwy; o wiele prościej wyrazić tę liczbę cyframi rzymskimi, a jeszcze zwięźlej - arabskimi. Notuje się zaś bądź pełną cyfrą rzymską, 1.132: anno Domini $M^{\circ} C C C C^{\circ} L V I I I^{\circ}$ (1458), bądź tylko jej cząstką końcową, 1.1021: anno etc. LX IX (1469); czasem częściowo cyfrą, a częściowo słowem, 1.63: L' septmo (1457), 1.206: anno Nativitatis eiusdem $M^{\circ} C C C C L$ nono (1459). Zapis arabski, anno $1494^{\circ}$, swą zwięzłością wziął górę nad pierwszym i wyparł go z praktyki codziennej.

4. Dies. Termin dies, tag, dzien nie jest jednoznaczny ${ }^{5}$.

a. Najczęściej to 24-godzinna doba składająca się $z$ dnia i nocy; łacina osobnego terminu na dobę nie zna. Ten właśnie sens dnia-doby występuje we wszystkich wypadkach, w których mówi się o okresach przedawnienia wynoszących często rok i d z i én, 1.1222: annum et die $m^{6}$.

b. Innym razem dies to (jasny) dzień, przeciwstawiający się (ciemnej) nocy, 1.198, 1447: tempus nocturnum, 2.383: tempore noctis, 1. 102, 103: bey $n a c h t^{7}$. Wchodzą one zatem $\mathrm{w}$ relacje antonimiczną ${ }^{8}$.

5. Dni e dzielą się z paru punktów widzenia. Podziały te się krzyżują.

a. Podstawowy jest podział na dni powszednie i świąteczne, inaczej: robocze i odświętne. Drugie cechują się tym, że praca ręczna jest wówczas zabroniona (SEJP). W tygodniu jest jeden dzień świąteczny: dominica, niedziela, a sześć - roboczych: feria secunda, tertia, quarta, quinta, sexta - aż do septima, sabbatum.

b. Odróżniamy święta stałe i ruchome. Tylko stałe przypadają na ten sam dzień roku, natomiast ruchome - na różne dni; i to znowu w ramach pewnych cykli.

c. Świąt stałych jest niewiele: Nativitas Domini (25 grudnia), Circumcisio Domini (1 stycznia), Epiphania (6 stycznia), Omnium Sanctorum (1 listopada). Będąc stalymi, pelnią one funkcję dodatkową - równocześnie datują̨.

${ }^{5}$ A. R óżyło, Obraz dnia i nocy w polszczyźnie, „Język Polski” 2002, t. LXXXII, s. 111-118.

${ }^{6} \mathrm{O}$ dies przeciwstawionej feria por. niżej pkt. 10) i $\mathrm{n}$.

${ }^{7}$ Dekrety notują również derywat 1.630: vor-nachten.

${ }^{8}$ A. Różyło, Obraz dnia..., s. 118. 
d. Reszta świąt, a wiẹc Pascha, Pentecosten, Trinitas, Ascensio Domini, przypada co roku w inne dni.

6. Rok kościelny dzieli się na kilka ok resów, które noszą osobne nazwy. Są to:

a) adventus, adwent, Przyjście (4 niedziele),

b) okres post Epiphanie,

c) okres po Objawieniu (3 niedziele), oraz

d) okres post Trinitatis, po Trójcy (26 niedziel).

7. W kalendarzu kościelnym również każda niedziela ma swoją nazwę, choć nie bez wyjątku: nie mają jej dwie - te, które wypadają na okres od 25 grudnia do 6 stycznia, a więc ostatnia - grudniowa i pierwsza - styczniowa. Zaznaczyliśmy wyżej, że nazwy niedziel stały się wtórnie terminami chronologicznymi. Uformowane zaś zostały na parę sposobów.

a. Raz zawdzięczają ją pozycji, jaką zajmują we wskazanych niżej okresach kościelnych.

b. Innym razem nazwę niedzieli stanowi pierwszy wyraz lub pierwsze wyrazy lekcji czytanej we mszy na daną niedzielę: Circumdederunt, Exsurge, Esto mihi, Invocavit, Reminiscere, Oculi, Letare, Iudica. Dwie następne to dominica Palmarum i Pascha. Dalej ida ponownie niedziele z nazwami uformowanymi od pierwszych słów lekcji: Quasimodo, Maiestas Domini, Jubilate, Cantate, Vocem Jocunditatis, Exaudi. Tę sekwencję przerywa niedziela Pentecosten (Piećdziesiątnicy, czyli Zeslania Ducha Świętego) oraz niedziela Trinitatis, po której idą 22 niedziele post Trinitatis, utrzymujące się aż do końca roku kościelnego.

8. Dominica, (dzień) Pański, niedziela, 2.736: die dominico Invocavit, 2.477, 478: dominico post Petri et Pauli apostolorum. Słowiański określnik, a więc $\mathrm{i}$ polski, nie nawiązal do terminologii lacińskiej, to jest ,do planet-bóstw, co im [misjonarzom] jawnym pogaństwem tracilo”, „lecz wytworzyl sie samodzielnie". Pochodzi już z VIII wieku".

a. Owa dominica, niedziela, upamiętniająca podstawowe zdarzenie świata chrześcijańskiego - Zmartwychwstanie Pańskie, jest najważniejszym, a zatem pierwszym dniem tygodnia ${ }^{10}$ i zawsze ś wi a t ec z n y m. W roku jest ich 52. Drugiego, równie częstego święta w kalendarzu kościelnym nie ma!

b. Sam termin dominica albo pojawia się w nagłówku dekretów. 2.558: ante dominicam Invocavit, 2702: post dominicam Iudica,

9 SEJP, s. 588.

${ }^{10} \mathrm{Na}$ jakimś nieporozumieniu polega twierdzenie Aleksandra Brücknera, jakoby kościól zaczynal liczenie [dni tygodnia] od soboty, SEJP, s. 528. 
albo się go pomija: 2.562: ante Oculi, choć oczywista tu zawsze domyślna: ante dominicam Oculi ${ }^{11}$.

9. Eta s, wi $e k$. Terminem tym dekrety nie poshugują się nigdy w znaczeniu stuletniego okresu. Taki sens mógłby się pojawić w traktacie chronologicznym, a nie w aktach notujących zdarzenia życia codziennego. Podobnie jak polski wiek, określa etas tę liczbę lat, którą jednostka przeżyla; stąd jej anni et a tis.

10. Feria, dzień tygodnia. Brak owego terminu w pracowitych indeksach, dolączonych do publikacji dekretów; może dlatego, że pojawia się on niemal w każdym nagłówku.

a. Średniowieczna feria różni się od klasycznej i formalnie, i semantycznie. $\mathrm{W}$ lacinie to plurale tantum feriae. Tymczasem $\mathrm{w}$ dekretach używano owego terminu najczęściej w liczbie pojedynczej - feria.

b. Ważniejsza różnica semantyczna. Dla Rzymian ferie były dniami świątecznymi przeznaczonymi na służbę bożą. Metonimicznie zaś stanowiły czas wolny od zajęć, dnie wypoczynku. SEJP daje trafną ich definicję: ,ferie wak acje oboje dla dni wolnych od pracy".

c. Tymczasem średniowieczna syngularna feria nie ma nic wspólnego $\mathrm{z}$ świętowaniem. Wskazuje ona zawsze i wyłącznie na dzień tygodnia - zarówno roboczy (od poniedziałku do soboty), jak świąteczny (niedziela)! W języku niemieckim istnieje dlań odpowiednik jednowyrazowy: Wochentag. Brak takiego $\mathrm{w}$ polskim, stąd $\mathrm{z}$ konieczności uformowane przez nas wyrażenie: dzień tygodnia.

d. Termin feria ma w dekretach całkiem inny sens niż dies, nie są zatem owe wyrazy synonimami. Stąd tak częste występowanie obydwu terminów obok siebie, 1.238: feria sexta, die i sancti Viti martyris; 2.366: feria tercia, die Appolonie; 2.417: feria secunda, die Arnoldi; 2.486: feria sexta, ipso die sancti Luce; 2.692: feria secunda, die sancti Vincencii.

e. Owych feryj, dni tygodnia, było oczywiście siedem: feria (prima); feria secunda; feria tercia; feria quarta; feria quinta; feria sexta; feria (septima).

f. Wszakże w dekretach powołuje się jedynie pięć ferii - od drugiej do szóstej, zatem bez pierwszej, tj. niedzieli, i bez siódmej, tj. soboty ${ }^{12}$.

${ }^{11}$ Charakterystyczne dla działalności krakowskiego sądu, że nieraz czynności prawnych dokonuje właśnie w niedzielę, 2.631: die dominico Rogacionum, 2.736: die dominico Invocavit, 2.1098: die dominico improfesto sancti Martini.

${ }_{12}$ Wyjaśnienie odrębnej nominacji polskiej, dlaczego feria tertia została wtorkiem, a więc dniem wtórym, d rugi m; feria quinta - czwartkiem, dniem $\mathrm{czw}$ a r y m, a feria sexta-piqtkiem, dniem piątym, daje J. Matuszewski, Slowiański tydzień. Geneza, struktura i nomenklatura, Łódż, 1978. 
Nigdy więc nie spotykamy tam wyrażeń feria prima, ani feria se p tima, albowiem pierwsze - to dominica, a ostatnie - to sabbatum. Owe dwa identyfikacyjne terminy wzięły górę nad określeniami liczbowymi.

g. W tygodniu wielkim ${ }^{13}$ wszystkie ferie były wielkie, zatem 2.650: feria quarta magna to "wielka środa", a 2.79: sabbato magno in vigilia Pasce, „w wielką sobotę, w wilię Paschy".

11. Od substantivum feria:

a. Zostały uformowane dwa przymiotniki, 2.30: feriatus i 2.778: feriatis, zawsze z domyślnym dies. Nie zdolaliśmy stwierdzić, czym się one semantycznie różnią; najprawdopodobniej sens ich identyczny.

b. Dies feriatus przeciwstawia się wielokrotnie dies solemnis, dies sacer; 2.544: tercio in eo errant, utrum solemni die vel feriat a sibi solvebat; 2.736: pars adversa facere debet post Conductum Pasche propter dies feriatos; 2.793: (sprzedaż ląki przez kobietę) hoc sola sine tutore, iudicialiter electo et in diebus feriatis, facere non potuit; 2.877: et eciam hoc decretum domini pallatini [...] factum est diebus feriatis, ubi non licet hereditatem iudicare [...] Quod autem dominus pallatinus cum consulibus et iuratis decrevit in diebus feriatis, hoc non est iuridice factum. A zatem dies feriatus byłby wedhug powyższych wypowiedzi dniem powszednim, roboczym.

12. Dodatkową trudność interpretacyjną sprawiają dekrety 1.313: in diebus ligatis videlicet feria quinta post Penthecosten [...] et post hoc eadem obligacio in diebus apertis, extraferiatis diebus [...] non est denuo renovata et confirmata, łącznie z 2.778: utrum sine iudicio bannito causa processum habere potest die feriali. Do wskazanych trudności dołącza tekst dalszy, 2.602: dixit: adventus sacri dies esse feriatos. Prawdopodobnie znaczyło to, że $w$ okresie adwentu dnie świąteczne stawały się roboczymi(?)

13. F est um. Każdy dzień roku - wiemy - ma swojego świętego patrona czy patronkę ${ }^{14}(1.246,415$ : festum Marie Magdalene, 1.252: festum Michaelis), albo też poświęcony zostal jakiemuś wydarzeniu ważnemu w liturgii kościelnej (1.329: festum Divisionis apostolorum, 1.307: festum Annunciacionis Marie, 1.440: festum Epyphanie, 1.711: ante Nativitatis sancte Marie Virginis festum. W istocie zatem w kalendarzu kościelnym na każdy dzień przypada jakieś $f$ e s t um. Wszakże - co należy podkreślić - termin ów nie zawiera już w dekretach sensu uroczystościowego, festivitas ${ }^{15}$.

${ }^{13}$ W dekretach nie zanotowaliśmy wyrażenia septimana magna.

${ }^{14}$ Kościół ma tylu świętych, że na jeden dzień przypada ich wielu, jak świadczą o tym Acta Sanctorum czy Acta Sanctorum ordinis sancti Benedicti.

${ }^{15} \mathrm{~W}$ indeksach Dekretów ostatni wyraz w ogóle się nie pojawia, choć notujemy go w nich parokrotnie, np. 1.291: ipsa die festivitatis (por. niżej pkt 19). 
14. Wyraz festum bywa często w tekście opuszczany, choć zawsze pozostaje domyślny, 2.912: post sancte Trinitatis oraz dekret następny, 2.913: post festum sancte Trinitatis, 1.822: post Valentini i zaraz 1.823: post festum sancti Valentini, 1.267: in feria sexta ante Martini, oczywiście: ante festum Martini, 1.239: feria tercia post (festum) Viti martyris, 2.356: post (festum) Iohannis, 1.908: sabbato post (festum) Katherine, 2.876: sabbato proximo post (festum) sancti Egidii. I wiele innych przykładów.

15. Festivitas. Termin używany w dekretach w sensie uroczystości świątecznej. Nieraz to wprost synonim do festum, 1.291: ipsa die festivitatis sancte Dorothee (por. wyżej pkt. 14).

16. Hora. Określeniem czasu jest również termin hora. Jaki jego sens? Nic nie daje wyrażenie 1.75: hor a consueta. Dopiero następujące 1.371: hora vesperorum, a zwlaszcza tekst 2.544: (świadkowie) nesciunt ho r a m, utrum mane, meridie vel vesper $e^{16}$ wyjaśniają sens terminu: to bynajmniej nie nasza sześćdziesięciominutowa godzina - na nią było za wcześnie, średniowiecze to przecież okres przedzegarkowy - lecz wyłącznie pora dnia!

17. Tych pór dnia znają dekrety cztery:

a) ra no, 2.544: $\operatorname{mane}^{17}$;

b) przed obiadem, 2.558: ante prandia;

c) w poludnie, 2.544: meridie;

d) przed zach odem słoń ca, 1.1529: usque solis ad occasum ${ }^{18} ; 2.558$ : hora vesperorum et ante solis occasum; 1.1099: paruit, suo iuri satisfacere volens, usque ad solis occasum; 2.108: pecuniam ad solis occasum reponere; 2.1054: actor se submisit coram iure et obligavit pecunias ponere [...] ad solis occasum; 2.747: hoc sibi solis ad occasum, sicut precium elaboratum solvere tenetur; 2.865: quod reus expensas actori XVI scotos taxatas ad solis occasum dare debuerat; 2.915: (rajcom, których strona dehonestavit et infamans eosque dicens indignos sedis huius - strona będąca zatem rebellis et protervus - cuilibet consulum luit per 36 solidos), quos eis reponere debet irremissibiliter ad solis occasum; 2.1007: a qua sentencia actor appellavit et melioravit taliter, quod pars rea docere debet ad occasum solis; 1.1099: (pozwany) paruit, suo iuri satisfacere volens usque ad solis occasum. Tej pory zachodu słońca należało zatem odczekać, 2.925: tunc non debuerunt decernere ipsum in ruina, sed exspectare solis o c c a sum et annotare de non satisfaccione diei ulterini.

${ }^{16}$ Tekst powolany został $w$ dekrecie dwukrotnie.

${ }^{17}$ Przypominamy spór o interpretację wyrażenia bonum mane; niektórzy historycy thumaczą owo wyrażenie przez dobrq ręke, manus, choć czwarta deklinacja takiego przypadka nie zna, por. J. M a tu szewski, Slowiański tydzień..

${ }^{18}$ Tak też dekrety $1.98,2.61,401$. 
18. Przytoczonym lacińskim terminom odpowiadają niemieckie: 1.736: $\mathrm{mor}$ gen (gabe), 309: bey Sonnenschein, 2.712: bis czu Sonne schein.

19. Wszystkie czynności prawne winny się dokonać $\mathbf{z a} \mathbf{d} \mathbf{n} \mathbf{i}$ a, a więc przed zachodem słońca. Po tym terminie wszelkie kroki poczytuje się za spóźnione, a w konsekwencji nieważne, 1.1286: tarde post occasum solis et non ante occasum solis paruit; 2.577: sed quia tarde fuit...; 2.1007: qui tunc propter brevitat em temporis probare non potuit.

20. Minuta. Wyraz dobrze dekretom znany, wszakże bynajmniej nie w znaczeniu czasowym, 1.668: quod minuta ostendit eciam ante citacionem, minut a eciam ostendit; 1.1058: iuxta min u t a m eiusdem concordie; 1.1129: sed pars adversa aliquas minut as introclusas una cum nostra sententia habere vellet; ...sed si eadem pars aliquas minutas vobis optat habere...; 1.1314: ex scriptis vestris et min u $t$ is sub sigillis vestri iudicii; 2.45: extunc super proposicionem actoris et responsionem partis respondentis prius debet sentencia proferri, quam aliqua $m$ in $u$ t a poni vel legi debeai; 2.532: postulavit sibi legi minutas; 2.541: et minute lecte sunt, 2.896: ex minut a bene perlegentes; 2.926: actor monstravit mani feste $m$ in u ta $m$ ex iure Cracoviensi, que coram iudicio vestro lecta est. W powołanych wszystkich przykładach i tylu innych jeszcze, które by można cytować, minuta to $\mathrm{zawsze}$ pisany tekst ${ }^{19}$, rẹkopis, a nigdy jednostka czasu. Przed rozpowszechnieniem się zegarków kieszonkowych tak mała jednostka temporalna, jak dzisiejsza minuta, nie znalazła, bo nie mogła znaleźć, praktycznego zastosowania ${ }^{20}$. A tym bardziej nie bylo miejsca na jeszcze mniejsza s ekunde.

21. O $\operatorname{cta} \boldsymbol{v} \boldsymbol{a}^{21}$, oktawa. Mimo siedmiodniowego tygodnia pojawia się w kalendarzu kościelnym często występujący okres zwany oktawą, 1.88: In o ctava festi Corporis Christi, 1.93: feria quinta infra octavas Visitationis, 1.105: sabbato infra oc ta vam Assumpcionis Marie, 1.158: feria quarta infra octavas Penthecostes, 2.1007: In octava Omnium Sanctorum. Genezę owego okresu stanowi średniowieczny sposób liczenia dni, zasadzający się na włączaniu do rachuby zarówno pierwszego dnia, od którego dokonywano obliczenia, jak i ostatniego, na którym liczenie kończono ${ }^{22}$. Taka operacja daje $w$ rezultacie sumę osiem.

22. Profestum. W dekretach notowano bardzo często dwa wyrażenia przyimkowe, 2.1091: ante festum oraz 1.66: post festum, przed i po święcie. Pierwsze zastępuje się nieraz rzeczownikiem złożonym

${ }^{19}$ Stąd też 1.762: minutarium - 'zbiór minut'.

${ }^{20}$ Zauważ: w dekretach termin minuta pełni również funkcję przymiolnika, 2.543: minuta pecunia, drobna moneta.

${ }^{21}$ Także w pluralis, octave.

${ }^{22}$ Der echte Tag nach einem Feste (mit Anfangs- und Endtermin), O. G rotefend, Taschenbuch der Zeitrechnung des deutschen Mittelalters und der Neuzeit, Hannover 1941, s. 19. 
profestum, zawsze w wyrażeniu in profest $0^{23}$. Jakie jego znaczenie? Wydawca zgodnie $\mathrm{z}$ etymologią slowa przyjąl, że to dzień poprzedzający inne festum. Zatem 2.882: feria quinta in profesto sancte Katherine to 24 listopada, bo dzień tej świętej przypada na 25 listopada; podobnie 2.1068: feria quinta in profes to Conversionis sancti Pauli to 21 stycznia, 2.1022: feria sexta in profesto sancti Iohannis Baptiste to 23 czerwca, a 2.1098: die dominico inprofes to sancti Martini to 10 listopada. I chyba jego stanowisko słuszne. Tym samym sens tego wyrażenia ostatecznie taki sam jak klasycznego in vigilia (por. pkt 28).

23. Quatember, quatuor tempora ${ }^{24}$. Ich polski odpowiednik to suchedni. Jak lacińska nazwa wskazuje, wypadają one cztery razy do roku 1.1255: quatuor temporibus, a to $\mathrm{w}$ marcu, czerwcu, wrześniu i grudniu ${ }^{25}$; 1.603: feria quarta quatuor temporum post festum Penthecostes, 1.1196: feria quarta quatuor temporum post festum sancte Lucie, 1.1292: feria sexta quatuor temporum post Lucie.

24. Quindena. Tak się zwie okres piętn a stu dni, wyznaczony stronie procesowej przez sąd na przeprowadzenie dowodu, 2.895: potest habere quindenam ad probandum.

25. Sabbat um, s o b o t a. Ostatni, siódmy dzień tygodnia, feria se p tima, brzmi z reguły sab b a t um, 1.224, 264: fuit feria s a b b a t $i, 1.764$ : feria $s a b b$ a to in die Invencionis sancta Crucis, 2.850: $s a b b$ a to, die sancti Briccii, 1.105: sabbato infra octavam Assumpcionis Marie, 1.821: $s a b b$ a to in die sancti Valentini, 1.894: $s$ a b b a to ante Hedwigis, 1.958: $s a b b$ a to proximo ante festum sancti Stanislai, 1.908: $s$ abb a to post Katherine, 1.010: sabbato post Martini, 1.1028: sabbato die, post festum Purificacionis Marie, 2.918: die sabbatri post sancti Procopii.

26. Niekiedy pojawia się postać przymiotnikowa lacińskiej soboty, 1.661: feria sabbatica ante Invocavit, 1. 706: feria die sabbatico infra octavas Assumpcionis Marie, 1.844: die sabbatico post Bonifacii.

27. Septimana, woche, tydzien. Jak lacińska nazwa wskazuje, jest to okres siedmiodniowy; zaczyna się on niedzielą, dominica, a kończy sobota ${ }^{26}$ sabbbatum. Indeksy lacińskie dekretów wyrazu nie zarejestrowały $\mathrm{w}$ ogóle, natomiast wykazana została $\mathrm{w} 2$. tomie niemiecka woche, 1.254, in sechz wochin, 1.895, 907: bey sechs woch in mynner adir

${ }^{23}$ Zwrot 2.831: die dominico inprofecto sancti Martini jest z pewnością zapisem omyłkowym.

${ }^{24}$ Wydawca drukuje owe wyrazy niepotrzebnie dużą literą; to nomina appellativa! Zaznaczmy: brak ich w indeksach do obydwu tomów.

${ }^{25}$ In ieiunio: estativum, autumnale, hiemale, vernale.

${ }^{26}$ Inny slownik jezyka polskiego PWN, Warszawa 2000, daje następującą definicję tygodnia: to okres siedmiu dni, liczony od poniedzialku do niedzieli lub od niedzieli do soboty. Mediewista przyjmie za własną jedynie rachubę drugą. 
mehe, adir wenig mehe. Podzial na tygodnie jest niezależny od innych; ma on zatem swój odrębny cursus, co wytworzyło w rachubie kalendarzowej niemałą komplikację.

28. Vigilia, czuwanie (SEJP). Utworzony z niej polski termin wprowadza w błąd. Kościelna vigilia to nie tylko przeddzień świąt Bożego Narodzenia, jak w dzisiejszej polszczyźnie, lecz w ogóle każdy dzień poprzedzający jakikolwiek inny ${ }^{27}, 1.85$ : in vigilia Penthecostes, 1501: in vigili a Marie Magdalene ${ }^{28}$.

29. Czasem pojawia się dodatkowe określenie czasu, konieczne wtedy, gdy jakiemuś ważniejszemu świętemu przypisano dwa lub więcej dni w roku, 2.274: in wigilia sancti Stanislai in a u tumno, czemu przeciwstawia się 1.958: sabbato proximo ante festum sancti Stanislai in mayo, 2.263: sabbathico die proximo sancti in mayo Stanislai, 2.295, 2.473: sabbato post Stanislai in mayo, 1.958: sabbato proximo ante festum sancti Stanislai in mayo.

30. W naszej toponimii mamy niejednokrotnie do czynienia $z$ nazwami miejscowości, które są powtórzeniem mian dni tygodnia: P on iedzia lek, W torek, Sroda, Czwartek ${ }^{29}$, Pią tek, S obota, Nie$\mathrm{dz}$ i e $1 \mathrm{a}^{30}$. Wzięły się one stąd, że w powołane dni odbywal się w danej miejscowości targ polączony $\mathrm{z}$ kościelnym odpustem ${ }^{31}$. Oczywiście tak określonych NM nie thumaczono na łacinę: trudno było oddać leżącą koło miejscowości Piqtku Sobote (por. sienkiewiczowski Potop!) przez Feria Septima, skoro rzeczownik sabbatum stanowił już datę czasu, sobotę; podobnie $\mathrm{i}$ z dalszymi terminami tygodniowymi. $\mathrm{Z}$ nimi nie mogły konkurować polskie NM. Silą rzeczy musiało się utrzymać ich brzmienie rodzime, bez thumaczenia.

${ }^{27}$ Jej dosłowne znaczenie kontynuuje francuskie substantivum la ve ille, jour qui precede celui dont on parle (Larousse).

${ }^{2 x}$ Starodawne przystowie polskie: wilia wilit/świetej Wiktoryi, wskazujące na dzień 23 grudnia, musi pochodzić $\mathrm{z}$ doby przed gregoriańską reformą kalendarza. Dzisiaj imię powołane przypada na 13 grudnia!

${ }^{29}$ Długos z, Liber beneficiorum, t. 3, s. 307: Czwartek - suburbium Lublinense.

${ }^{30}$ Slownik Geograficzny Królestwa Polskiego i krajów squsiednich.

${ }^{31}$ Ob. K. Maleczyński, Najstarsze targi $w$ Polsce $i$ stosunek ich do miast przed kolonizacja na prawie niemieckiem, [Lwów] 1926, SHPP, t. 10, z. 1. 